\title{
From ESA to ESCAPE: A conceptual model for teaching English in vocational higher education
}

\author{
Musdariah, Andi \\ State Polytechnic of Ujung Pandang, Indonesia (musdariahandi@yahoo.com) \\ Anas, Ismail $\$ \\ State Polytechnic of Ujung Pandang, Indonesia (ismailanas@poliupg.ac.id) \\ Muchtar, Naely \\ State Polytechnic of Ujung Pandang, Indonesia (naelymuchtar@ymail.com)
}

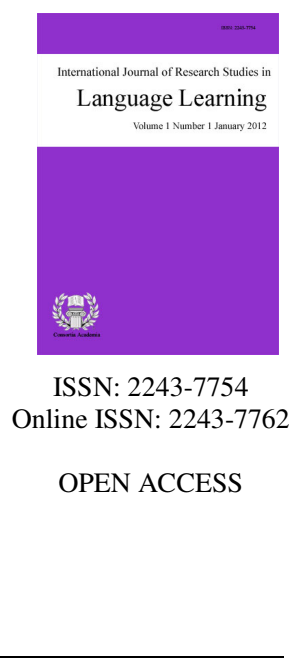

\section{Abstract}

The study develops a modified model generating a procedural guide in lesson planning construction for teaching English within the Vocational Higher Education (VHE). The work elaborates six essential elements in constructing ELT lesson plan, they are: engage, study, create, activate, practice, and evaluate, and it is so-called ESCAPE. Each element of the model represents pedagogical theories and practical approaches that constitute a guided direction and/or instruction for the construction of a practice-based teaching lesson plan. The study employed Research and Development (R\&D) design through a focus group discussion (FGD) involving three experts specializing on ELT methodology, English course material development, and English curriculum development. A RASCH measurement analysis using WINSTEP and Factor Analysis using SPSS were employed in the study. The work suggests this modified model to be used in VHE and recommends further development on pedagogical theories underpinning each element, clarity of instructions, and method of implementation. Some limitations to this model were also identified.

Keywords: ESCAPE; ELT; lesson plan; Vocational Higher Education (VHE) 


\section{From ESA to ESCAPE: A conceptual model for teaching English in vocational higher education}

\section{Introduction}

The teaching of English in Vocational Higher Education (Polytechnics) in Indonesia has become more and more urgent toward AFTA (Asian Free Trade Area) in 2015. The multidisciplinary courses within the VHE require the English language teachers to employ an appropriate approach to reach the learning goals and objectives. Hu (2011) states that "The combination of English and vocational knowledge has effectively helped the students to produce instance of language use in their life and work"(Hu, 2011). It can be implied that the integration between English and vocational knowledge in multidisciplinary courses is effective in promoting a communicative language skill. Integrating English and vocational knowledge into classroom teaching needs vigorous efforts to meet the need of service industries. In the context of VHE, the English curriculum applies a dominant portion of practical teaching across the multidisciplinary courses that make a merit of a major attention from teachers as course developers. The KKNI (National Qualification Framework of Indonesia)-based curriculum has brought new paradigm, demands, and challenges into the course selection procedures, course content material development, and its dissemination in classroom teaching.

The importance of practical learning in multidisciplinary courses within the VHE towards global competition has increased the awareness of vocational higher institutions in providing a highly skilled workforce to meet the needs of service industries (Kehoe, 2007). One of the most important skills is English communication proficiency. Some studies had been conducted to investigate the needs of English communication in workplace (Huhta \& Sciences, 2010; Kassim \& Ali, 2010; Mohamed et al., 2014). To promote a high quality teaching of English within the VHE, updated innovation in teaching methodologies and approaches should be effective and well-developed.

In terms of novelty, a very view literature in the area of ESCAPE was discussed in recent publication although there have been many studies conducted in the field of ESP. The studies on the elements of ESCAPE have shown a rigorous effort from many scientists and researchers to make investigation on how to engage students in learning (Aboudan, 2011; Davis, Summers, \& Miller, 2012; Dredger, Woods, Beach, \& Sagstetter, 2010; Perrone, 1994; Prensky, 2005), to study (Robertson \& Acklam, 2000), to create a video for learning (Rao, Hitchcock, Boisvert, Kilpatrick, \& Corbiell, 2012), to activate (Lewis \& Thompson, 2010), but less attention to combine those findings into an integrated teaching method and approach. Conceptually, this model proposes a new method and approach to teaching English in VHE. This study explores and develops a practical guide for EFL teachers to be used in constructing an English lesson plan. In line with the VHE curriculum demands and expectations, this model fits the standards of teaching in that $70 \%$ of the total allotted time of the course is for a practical based learning while the rest $30 \%$ is for theoretical based learning.

This research will bring of much benefit to the teaching of English particularly for English lecturers among the multidisciplinary courses within the VHE. In Indonesia, there are 38 state polytechnics spread across the archipelago from east to west that serve a vocational and skill-oriented education. With this conceptual model, it will contribute to the teacher development and professional work. From past to current ELT in VHE, the teaching of English still applies a lecture-based teaching methodology where the students often get bored. The 2-way communication needs to be built and constructed to create an intense interaction between teacher and students. ESCAPE offers an opportunity to make a significant change in the way people teach English in VHE by providing an outline of ESCAPE-based lesson plan in which teachers can design and create an interactive teaching with more content of practice activities during the lesson. To the best of this model, further research and development within this area will need to be conducted. 


\subsection{Literature review}

Stepping from the previous model ESA (engage, study, and activate) that these three element should be present in every teaching sequence (Robertson \& Acklam, 2000). In the context of teaching English within the VHE, this model should include other elements that fit the curriculum demands and expectation. The model is not also necessarily and merely a guide as to what order activities should come first and how long it will take. This model conceptually involves six elements of pedagogical properties that constitute a practical-based teaching for teaching English in Vocational Higher Education (VHE).

“...learning is not a spectator sport. Students do not learn much just by sitting in classes listening to teachers, memorizing pre-packaged assignments, and spitting out answers. They must talk about what they are learning, write about it, related it to past experiences and apply it to their daily lives. They must make what they learn part of themselves." (Chickering \& Gamson, 1987)

In contradiction with modern teaching and learning perspective, traditional methodology in teaching is a teacher-centered approach that posits an authoritative standpoint which is strongly associated with one-way communication and knowledge transferring method (Boumová, 2008). A recent observation in the area of teaching methodology and its implementation within six departments in State Polytechnic of Ujung Pandang which consists of engineering and non-engineering reported that most of the teachers are still teacher-centered with traditional approach (UP3AI, 2014). Recent study on a changing paradigm reporting a shifted methodology from teacher-centered to learner-centered teaching classroom using multimedia has also been reported (Li, 2016 in press). In response to this situation, a professional development relating to the improvement of the teacher competence is necessarily needed.

\subsection{From ESA to ESCAPE}

The previous model ESA (engage, study, and activate) was mainly initiated to teaching English in general context in which the ELT within the VHE expects a high demand on practical activities rather than theoretical approach. The three elements in ESA will need to be adjusted and developed to meet the expectation of VHE curriculum. The VHE curriculum requires more practice to be included in every teaching in which $70 \%$ of the total allotted time should be provided for practice sessions and the rest $30 \%$ should be allotted to theoretical teaching. To meet this expectation, a model should be developed that include more practice sessions within it. To fit the modified model, three elements are added to the previous model ESA generating the new model ESCAPE as an umbrella of teaching English in VHE. The three elements are create, practice, and evaluate in which they are all carrying the essential meaning to practical teaching concept. With the addition of those three elements, the new model ESCAPE will help teachers create and design a practice-based lesson plan and perform an interactive teaching and learning between teacher/lecturer and students.

Six elements with pedagogical concept constituting the model ESCAPE are described in the following overviews:

Engage - Based on the learner-centered approach, student must be pro-active during the learning process. To create a successful teaching, a teacher-centered approach should be avoided in order to bring more opportunities to students in exploring the process of learning. The student's participation will depend on how much the students are engaged in (Bean, 2004). In relation to the student's participation, it is very important to get the students participate, to capture, and to sustain their interest in learning environment (Aboudan, 2011).

There are many ways and methodologies that teacher can use in engaging and increasing the student participation in classroom. One of the ways to increase the student's participation in writing lesson is using new literacy to create third space classrooms (Dredger et al., 2010). 
Musdariah, A., Anas, I., \& Muchtar, N.

...All the students we teach have something in their lives that's really engaging something that they do and that they are good at, something that has an engaging, creative component to it. (Prensky, 2005)

The student are engaged and motivated if they know what to do, meet their need and interest, feel secure and comfortable, and are positively encouraged. Teacher may find it stressful when facing demotivated student and uncontrolled classroom situation. In this kind of classroom situation, a role of creative teacher is necessarily needed to well-organize the learning environment. The students need to know what they are going to do and accomplish and a teacher should organize an engaging class opening by selecting strategy and appropriate methodology to lead the student to the learning content.

In terms of students engagement in learning environment, there are three types of engagement that promote the student's participation in classroom learning context, they are: (1) cognitive engagement, (2) behavioral engagement, and (3) relational engagement (Davis et al., 2012). Relational engagement exposes the connection and good communication both teacher and student that promote the motivation, performance and understanding of academic content. This suggests that the teacher should form a good relation with the student in order to get them engaged in. It can also be inferred that disharmonic relation between the both teacher and student will lead to miscommunication and potentially demotivate the student. In behavioral engagement, the student's pattern of behavior and participation in the classroom affect the motivation, performance, and understanding of academic content. The more the students motivated and involved in the learning process, the more the student will get engaged in and promote the participation and performance. The third is cognitive engagement that posits the student's emotional and cognitive investment in the learning process affect the student's performance and understanding of academic content. In this case, the teacher has an important role in translating those three interrelated engagement into a teaching and learning context.

It is very important to understand how to get the student engaged in the lesson and to determine the appropriate strategy. Although the level of engagement is rather difficult to measure (Parsons \& Taylor, 2011), the student engagement can be attained if the following prerequisites are met:

$>$ The students are highly motivated

$>$ A high student participation in the lesson

$>$ The students are interested in the lesson

$>$ Teacher-student interactive communication is formed (asking question, responding, commenting, and following request)

$>$ The presence of positive reaction of student (laughing, shouting, smiling, and many others)

Study - An excellent and well-organized material presentation following the practice is the key for teaching success in which the students need a clear overview and description of what they are going to do and how to do it (Harmer, 1998, 2007). An appropriate methodology, approach, and strategy selection to be used in teaching determine the process of knowledge transferring. To achieve the instructional learning purposes, the students must have a good understanding of what is being learned. The role of teacher in this stage is to transform the knowledge through the many strategies of material presentation that allow students to grasp the lesson effectively.

In an English language teaching classroom there needs to be some language focus for the class and/or related to the goals and objectives of the lesson (Robertson \& Acklam, 2000). Within this material presentation session, the teacher will have some time to direct and elaborate the language focus in order to provide the students with initial understanding and comprehension before doing the practice. The students must be introduced the theoretical background underpinning the subject matter. The following are the prerequisites of the element "study":

Material presentation (theories, cases, phenomenon, experience, and many others) 
$>$ Language focus presentation

$>$ Tutorial for students

$>$ Availability of learning resources (book, module, journal, generic, and online learning resources via internet)

Create - The creation of something through a creativity and imagination is the representation of what someone already know. If the students have enough understanding of what they are going to do, they definitely will do more and be able to communicate the relevant ideas related to their work. One of the creativities related to English language learning is reflecting ideas and knowledge through a picture story, illustration, photography, self-made video, self-sound recording. If a teacher asks the student to draw a picture of what the students are familiar with, they will have more chance to explore their creativity and be able to give a clear and detail description about their work. In terms of English language teaching and learning, a picture story is one of the many samples of creation in learning while some other possibilities may be adopted and applied in the classroom such as self-made video making, self-sound recording, and even a group work. It is simply better to have the students create something for their own learning rather than to ask what they must do.

For instance, a teacher asks a student to describe the favorite room or place in his house and he would rather tell what was flashing across his mind about his house and the story seemed to be not well-organized. As a comparison to this case, a teacher asks a student to make an illustration, a simple drawing, and/or simple video about the room that he likes much and then ask him to present his work in front of the class. As a result, the student felt confident, highly motivated, enthusiastic, and respected of what he has done and created. Giving a space to student to explore, experience, and share would increase the student participation and involvement in the lesson and it is highly potential for the student to create better than the teacher expected (Rocca, 2010).

The presence of the element creates in the lesson should meet the following prerequisites:

$>$ Self-made project (filming or video-taking, recording or sound production, editing or multimedia creation)

$>$ Group-made project (filming or video-taking, recording or sound production, editing or multimedia creation)

$>$ Task-based activity (composing, narrating, drawing, figuring, blogging, and many others)

$>$ Imaging (Photo taking, picture story, etc.)

$>$ Class project or workshop on particular topic

Activate - Referring to what the students have learned and studied, the information, knowledge, understanding, and comprehension needs to be activated. The students should be given time and space to activate it through some strategies of knowledge activation. Giving feedback, suggestion, critic, and comment on student work would potentially promote the students eagerness and willingness to involve and take part in the learning activities. The purpose of this element is to develop the knowledge, enrich the comprehension, and deepen understanding. Activating strategies should be formulated to briefly guide the teacher in directing and facilitating students in learning. Activating strategies should meet the lesson goals and objectives in that the teacher should appropriately pick the effective way to be used in classroom teaching (Lewis \& Thompson, 2010). Although the activating strategy is rather difficult to be figured out by most teachers, this session of teaching should come to an important consideration in order to address the student understanding and comprehension.

$>$ The following are some prerequisites generated from the element of activate

$>$ Teacher provides exercises

$>$ Teacher uses worksheets

$>$ Teacher administers quizzes and/or mini test

$>$ Teacher conducts an interview 
Musdariah, A., Anas, I., \& Muchtar, N.

Providing some exercises (i.e. chapter exercise, worksheet, interview, and many others) for students to work on would help to build up understanding and comprehension of what previously the students have learned and studied. These kind of exercises should be present in teaching and learning activities to ensure that the teaching and learning goals and objectives are met.

Practice - The most important stage out of the six element is practice in which this session provides more chances for both teacher and student to transform their knowledge into practice. In English language teaching and learning context, this slot is to provide more time to practice the communication skill using English. The student must be able to communicate ideas, opinion, understanding, and comprehension of the subject matter. For example, in engineering program the student are expected to be able to communicate how to start the engine, overhaul a machine, and troubleshoot some engine problems. To do so, the students must have an understanding how to do those things theoretically and practically. Another example from non-engineering perspective, the practice can be done through a simulation and role play to figure out how something works. In business administration program, the students are expected to be able to deliver a business presentation in English. To do so, the students are firstly equipped with an understanding how to deliver a business presentation by outlining some theoretical background from some related resources such as book, journal, and even videos. Secondly, the students are given chance to design their own presentation (create) and finally come to the practice session. The more we do practice, the more we will understand the subject-and so-known "practice makes perfect" (Kehoe, 2007).

In this stage, teacher is expected to be able to design, construct procedural steps, and determine an appropriate strategy on how to get the students actively involved and engaged in. To attain and to work better in this stage, the following prerequisites should come to a consideration in order to better provide a good practice:

$>$ Student practice with role play

$>$ Procedural activity using job sheet

$>$ Student performance through a presentation (individual and group presentation)

$>$ Building up student communication skill through pair and group work conversation (pair and group discussion)

Evaluate - In order to better understand how excellent the students are progressing during the lesson, an evaluation should be taken into account to provide a useful feedback for the pupils. The evaluation aims at providing a description of student achievement. The assessment of the student's progress can be done through some evaluation strategies such as pre-evaluation, whilst evaluation, and post evaluation. The following are some prerequisites of classroom learning evaluation and assessment

Teacher gives correction

$>$ Teacher gives feedback

$>$ Teacher gives comment

$>$ Teacher gives suggestion

$>$ Teacher gives critics, and

$>$ Teacher gives advice

Giving correction will help the students learn from the mistake and make improvement in the future. Giving feedback to students would promote the student participation and engagement in the lesson (Spiller, 2009). Those types of evaluation will bring benefit to both teacher and students.

\section{Method}

\subsection{Research design}

This research employed a mixed-method approach involving both qualitative and quantitative in nature. The 
research began with synthesizing the pedagogical theories underpinning the six elements of conceptual model generating an initial draft of ESCAPE. This research employed a Focus Group Discussion (FGD) involving three experts from different expertise (course and material development, language research methodology, and ESP), 8 English lecturers, and 25 student's representatives were conducted. The FGD generates a conceptual model of ESCAPE with measurable indicators for each element. The elements, as it is so-called variables, constituting the ESCAPE are described throughout a questionnaire based on the construct variables.

\subsection{Instruments}

Instrument validity with RASCH - The continuation of research instrumentation went through two steps of instrument validity and reliability. The process of measuring the instrument validity and reliability involves the persons (participants) and items (questions) reliability. The measurement intended to see the logit value of both person and item to obtain an empirical data and evidence of instrument that measures. During the process of instrument validity, the structure of questionnaire was fit through several alteration and modification on misfit items. The participants involved in instrument validity were 40 random-selected participants considering the minimum participants required in RASCH model measurement and analysis was 30 people.

Questionnaire - Fundamentally, the questionnaire was developed in two versions (student and lecturer) containing different questions. The lecturer version was developed to obtain information on how they perceived the model ESCAPE and its implementation in their classrooms. For the student version, the questionnaire was developed based on the construct variables resulted from the FGD representing all six elements that constitute ESCAPE. The sixth elements are: 1) engage [21 questions], 2) study [11 questions], 3) create [10 questions], 4) activate [10 questions], 5) practice [9 questions], 6) evaluate [10 questions]. The questionnaire was constructed on google form and spread out online to the participants. The selection of online survey was based on the type of analysis employed in the research (RASCH) in which the analysis was able to validate the persons taking the survey and to determine the extreme (unreliable) respondents/participants.

Classroom observation - To see how well the lecturers perceive the conceptual model ESCAPE and its practice in real classroom, an observation was conducted in 7 different classrooms taught by different lecturers. A partial observation was initiated to objectively and comprehensively evaluate the concept. The observation was intended to see the implementation of ESCAPE-based lesson plan generated from the elements of the model. The result of this observation is also qualitatively described in this paper.

\subsection{Data analysis}

The measurement method employed a RASCH analysis using WINSTEP software and factor analysis using SPSS (Bond \& M.Fox, 2015; Sumintono \& Widhiarso, 2013). Quantitatively, the data obtained from the questionnaire were basically ordinal containing a likert rating scale meaning it cannot be processed through arithmetic calculation since the data doesn't represent an equal interval value. The result of the analysis presents the person and the item logit indicating the interval value of person and item reliability. Qualitatively, the result of observation conducted in 7 classrooms is also presented descriptively.

\section{Result}

\subsection{Conceptualizing ESCAPE through Focus Group Discussion (FGD)}

The initial draft of ESCAPE was presented in an academic forum called Focus Group Discussion (FGD) attended by three experts in ELT (one professor and two associate professors), ELT professionals and students. The FGD was initiated to match and link the pedagogical theories and the practice in ELT classroom within the VHE (polytechnic). The FGD began with presentation of the initial draft of ESCAPE elaborating the theoretical considerations underpinning each element of the model with the construct variables that constitute the concept. 


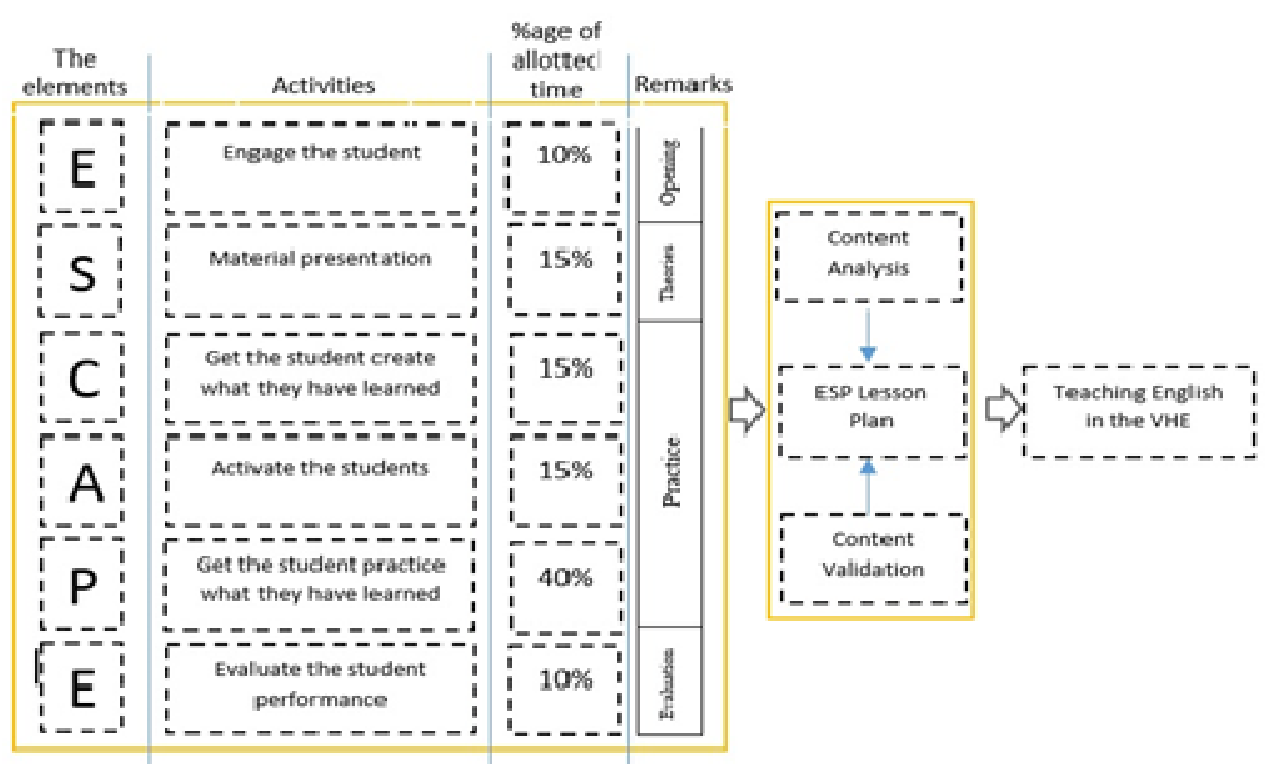

Figure 1. Conceptual model of ECAPE

Figure 1 illustrate the conceptual model of ESCAPE as an umbrella for teaching English in Vocational Higher Education (VHE). The model consists of six elements in which each element represents a pedagogical concept on how the teaching should be. The allotted time is the estimated length of activity duration of each stage, so the teacher can easily manage the activities during the lesson. The practice session falls within the CAP (create, activate, and practice element) where the students are given opportunities to do more practice. At the very beginning (engage), the students will need to be engaged in the lesson such as doing some activities that can motivate the student to participate in the lesson (see subsection engage). It is simply important to get the students engaged because the student' participation depends on the student motivation and interest. If the students are interested in the lesson, they will be engaged easily to participate.

Following the engagement session, teacher comes to study session where the teacher performs a material presentation (theoretical-based learning). The material presentation is important to provide the students with a better understanding on the subject (see subsection study). It is assumed that the students have enough understanding in the study session, the next step is create session where the students are given opportunity to make a creation relating to the lesson (see subsection create). The next session is activate session where the students understanding needs to be activated to ensure that the students have enough understanding on what they have learned (see subsection activate). The main session of this activity is practice session where students are given a space and more time to do practices. The practice is designed and developed by the teacher/lecturer. There are many kinds of activities that lecturer can do in this stage depending on the topic of the lesson (see subsection practice). The final session is evaluate in which this session is set to evaluate the learning progress. It is important to include this session in order to provide feedback to learners and to do assessment (see subsection evaluate).

The FGD suggests some limitations (see some limitation to ESCAPE) and suggestions for further development of the model. In the context of VHE (polytechnic), this model needs some adjustment and development to meet the various expectation of many different learning needs across the multidisciplinary courses within the VHE (polytechnic). In general, the model has provided a conceptual model in constructing and designing lesson plan for teaching English in vocational higher education (polytechnic) and already accepted by the focus group. This conceptual model provides a prototype and an umbrella of teaching English within the polytechnics. The model can be further developed to give more flexibilities in content creation and material development. 


\subsection{Instrument validation (attempt 1)}

An instrument consisting 43 statements that represents the six elements of ESCAPE was spread out to 40 students within the VHE. The students were randomly selected across the multidisciplinary study programs. An online Google form questionnaire (http://goo.gl/forms/ONHG0FS7mO) was used to collect data from the respondents and it was then exported to a spreadsheet Microsoft excel for further analysis. This validation aimed at providing empirical data that statistically measured the construct variables of each element of the model. The data which has been obtained and exported was analyzed using RASCH measurement model. The RASCH analysis was mainly generating two empirical information, they are: (1) person logit, and (2) item logit. The person logit presents the logit value within the equal interval measurement indicating whether or not the persons or respondents are reliable. At the same time, the item logit of 43 questions was also presented through a construct map indicating the logit value of each item (question) for item reliability. By using software WINSTEP as a tool for analysis, the following is the summary of person and item measured of 40 respondents.

Table 1

Summary of measured person and item (attempt 1)

\begin{tabular}{llccccc}
\hline No & $\begin{array}{c}\text { The } \\
\text { elements }\end{array}$ & $\begin{array}{c}\text { Person } \\
\text { reliability }\end{array}$ & $\begin{array}{c}\text { Item } \\
\text { reliability }\end{array}$ & $\begin{array}{c}\text { Separation } \\
\text { (person) }\end{array}$ & $\begin{array}{c}\text { Separation } \\
\text { (item) }\end{array}$ & $\begin{array}{c}\text { Cronbach } \\
\text { Alpha }\end{array}$ \\
\hline 1 & Engage & 0.95 & 0.88 & 4.16 & 2.77 & 0.96 \\
2 & Study & 0.74 & 0.90 & 1.67 & 2.94 & 0.78 \\
3 & Create & 0.80 & 0.80 & 1.20 & 2.00 & 0.80 \\
4 & Activate & 0.59 & 0.33 & 1.19 & 0.71 & 0.00 \\
5 & Practice & 0.71 & 0.75 & 1.55 & 1.71 & 0.83 \\
6 & Evaluate & 0.66 & 0.89 & 1.39 & 2.82 & 0.92 \\
\hline
\end{tabular}

Table 1 illustrates the summary of measured person and item presenting the person reliability, item reliability, separation value of person and item, and cronbach alpha. The person reliability shows that the element engage, study, create, and practice are reliable meaning the respondents can be trusted in giving responses to the questionnaire. The rest two elements (activate and evaluate) shows that, in general, the respondents seemed to be difficult to figure out the item. This point suggests that a revision for item clarity should be reconstructed. In line with person reliability, the item reliability of activate shows the similar trend in which the items are poor in quality and potentially unable to measure the variable.

\subsection{Instrument validation (Attempt 2)}

Based on the instrument validation (attempt 1), a modification and improvement had been done to the element activate in which the person and item reliability was below the minimum standard required in RASCH (see table 1). The improvement was to modify and add some questions that represent the element. The questionnaire was launched for the second attempt through online survey using Google form (http://goo.gl/forms/DTd3EpP3ni). From the survey, there were 36 students participated in and had met the minimum standard of participant in RASCH analysis and measurement model.

\section{Table 2}

Summary of measured person and item (attempt 2)

\begin{tabular}{llccccc}
\hline No & $\begin{array}{c}\text { The } \\
\text { elements }\end{array}$ & $\begin{array}{c}\text { Person } \\
\text { reliability }\end{array}$ & $\begin{array}{c}\text { Item } \\
\text { reliability }\end{array}$ & $\begin{array}{c}\text { Separation } \\
\text { (person) }\end{array}$ & $\begin{array}{c}\text { Separation } \\
\text { (item) }\end{array}$ & $\begin{array}{c}\text { Cronbach } \\
\text { Alpha }\end{array}$ \\
\hline 1 & Engage & 0.89 & 0.89 & 2.80 & 2.91 & 0.92 \\
2 & Study & 0.72 & 0.95 & 1.60 & 4.38 & 0.68 \\
3 & Create & 0.81 & 0.86 & 2.08 & 2.50 & 0.79 \\
4 & Activate & 0.63 & 0.87 & 1.31 & 2.61 & 0.69 \\
5 & Practice & 0.88 & 0.89 & 2.73 & 2.86 & 0.77 \\
6 & Evaluate & 0.58 & 0.81 & 1.18 & 2.07 & 0.84 \\
\hline \multicolumn{2}{l}{ Notes. Winstep RASCH analysis }
\end{tabular}


Table 2 illustrate the questionnaire test (attempt 2) presenting the result of analysis on each element of the model. A significant improvement shown in the table above is in the element activate where the person reliability raised from 0.59 to 0.63 and so did the item reliability that raised from 0.33 to 0.87 (see table 1 ). It can be concluded that the construct variable activate is reliable and measurable. The whole analysis

\subsection{Factor Analysis}

The data resulted from RASCH analysis is then further analyzed through a factor analysis with SPSS. The following tables are viewing the result of factor analysis representing the variables of the model. The analysis aims at measuring the interrelated correlation among the variables in which they are conceptually constituting the model.

The expected value of KMO and Bartlett test to see the correlation among the variables is $>0.5$. It can be concluded that a further analysis can be administered since the value of KMO is 0.853 meaning higher than the expected value (see appendices). To see the correlation among the variables, the following table (table 3 ) provides an illustration of Measure of Sampling Adequacy (MSA).

\section{Table 3}

Summary of factor analysis

\begin{tabular}{clcccc}
\hline No & Factors & $\begin{array}{c}\text { Anti-image } \\
\text { correlation }\end{array}$ & $\begin{array}{c}\text { Communalities } \\
\text { value }\end{array}$ & $\begin{array}{c}\text { Anti-image } \\
\text { covariance }\end{array}$ & $\begin{array}{c}\text { Sig. (1- tailed) } \\
\text { correlation }\end{array}$ \\
\hline 1 & Engage & 0.88 & 0.79 & 0.27 & $<0.05$ \\
2 & Study & 0.84 & 0.73 & 0.28 & $<0.05$ \\
3 & Create & 0.81 & 0.45 & 0.54 & $<0.05$ \\
4 & Activate & 0.87 & 0.59 & 0.46 & $<0.05$ \\
5 & Practice & 0.82 & 0.86 & 0.20 & $<0.05$ \\
6 & Evaluate & 0.89 & 0.73 & 0.33 & $<0.05$ \\
\hline
\end{tabular}

Notes. SPSS factor analysis

The MSA value is ranging from 0 to 1 under three major conditions, they are; 1) MSA=1 meaning the variable is predictable without any errors to other variables, 2) MSA $>0.5$ meaning the variable is still predictable and valid for further analysis, 3) MSA $<0.5$ meaning the variable is unpredictable and invalid for further analysis. Consequently, the variable is subject to be eliminated. From the table 4 above, the MSA value within the Anti-image Correlation is higher than 0.5 (engage: 0.880, study: 0.837, create: 0.813, activate: 0.874 , practice: 0.820 , and evaluate: 0.893 ) meaning that the variables are significantly correlated. In the other hand, the communalities value posits the extraction measured scores that measure the possibility of factors to describe the variables (engage: 0.793 [79.3\%], study: 0.732 [73.2\%], create: 0.451 [45.1\%], activate 0.591 [59.1\%], practice 0.867 [86.7\%], and evaluate: 0,730 [73\%]).

The correlation among the variables is shown in table 3 above. The correlation matrix illustrates a positive correlation among the six variables. The significance of the variables correlation is shown through the sig.(1-tailed) measures that illustrate the p-value $<0.05$ meaning that there is a correlation among the variables. An unusual correlation is identified between the variable create and evaluate since the value sig.(1-tailed) is reported 0.08 (>0.05) meaning that there is strong correlation between the two variables.

\subsection{Implication for practice, learners, and teachers}

In Indonesian context, the practice of English language teaching within VHE needs a practical guide as an umbrella to help teachers prepare for the class, design a lesson plan, set an activity, and organize their classrooms. This initial and new-developed model will need to be evaluated for better use in the future considering the different learning settings among the multidisciplinary courses within the VHE. The needs, goals, objectives, and expectations of each discipline require a strategic approach. The implication for future practice, learners, and teachers are outlined in the following standpoints: 
$>$ The availability of a conceptual model in teaching English in Vocational Higher Education (VHE) will help lecturers to design and create a practical-based teaching and learning. The contribution of this model is addressed to teaching methodology and practice in which the model offers a new paradigm in teaching English within the VHE. From the past to the present, most of the teaching practices still base on the conventional teaching paradigm where students were inactive learning participants.

$>$ Reducing teacher talking time (TTT) and increasing student talking time (STT). With this model, the lecturer will able to organize some activities that allow students to participate more in the classroom. The increase of student' participation will be of much benefit to improve the students' ability and performance in classroom.

$>$ Generally, the model has initiated a two-way communication and interaction among the students and the teachers as well. Students were given more time to do more practices such as discussion, pinwork, presentation, role-play, and simulation. The students were engaged and motivated in participating in their learning although the model is sometime perceived incorrectly by the teacher.

$>$ From the teachers' perspective, they found the model not working in TOEFL class since it was designed and developed for classroom activities and participation.

From students' perspective, the use of this model will allow them to more participate and engage in learning activities where they can get enough time to do more practices. The previous method, as it is called conventional method or lecture-based teaching is no longer effective to students since the practice time slot was limited

\subsection{Some limitations to ESCAPE}

Although this initial model is specifically designed for teaching English within the VHE (polytechnic), it has some limitations in fit to the various needs of English learning and learning expectation across the multidisciplinary courses. To better use the application of this model within the VHE, this study suggests some limitations to consider as follow:

$>$ ESCAPE provides a prototype or an "umbrella" for teaching English in Vocational Higher Education (polytechnic). It is also important to notice that this initial model is designed for guiding EFL teachers/lecturers in constructing lesson plan for specific purposes. A further research and development needs to be taken into account that the interpretation, creativity, learning content, media, literacy, tools, and other resources rely on teachers' experience, knowledge, and performance in the classroom.

$>$ ESCAPE doesn't provide any specific guideline, supplementary, tools, and media for teaching the four language skills (speaking, writing, reading, and listening). Further studies will fall within these areas.

$>$ To use this model, it is very important to set the learning goals and objectives in order to better design and construct an ESCAPE-based lesson plan.

$>$ In the context of polytechnic, teaching English within the multidisciplinary courses (an ESP) should first identify characteristic of learners and so do the materials available. Once they are identified, a teacher/lecturer can transform the idea into ESCAPE teaching model. It allows the teacher/lecturer to determine what activities should go into teaching stages representing the element of ESCAPE. Knowing how to best engage, deliver the material, boost the student creativity, activate the student understanding, provide an effective practice for specific goal, and fairly assess the students will help teachers/lecturers to work on ESCAPE effectively. 


\section{Conclusion}

This initial model of teaching English in Vocational Higher Education (Polytechnic) has brought a new innovation to ESP teaching perspective. The important of innovation in education will make changes to the learning atmosphere (see Braun \& Kanjee, 2006; Fagerberg \& Srholec, 2010). Further research and development should fall within the area of English language skills (speaking, writing, reading, and listening). Knowing the essential structure underpinning this model will help teachers/lecturer understand, comprehend, and use this model in their EFL classrooms. The implementation of this model will vary depending on how this model is perceived. In relation to this, there are three main factors contributing to the best use of this model, they are: 1) a valid model (ESCAPE), 2) teachers ability and competence to perceive the model, and 3) the students acceptance. Although a new concept and innovation has been empirically tested and validated, it will not be running without an adequate support from teachers as an actor in classroom. The area of investigation will also include teachers as influential determinant in the learning process.

The following are some suggestions and recommendation for further research to develop this model:

$>$ Revision on instructional guideline within the ESCAPE handbook should be developed particularly each element constituting the model. Since it is a new-developed model, more pilot tests should be undertaken to create a stable model that meets the need of ESP curriculum.

$>\quad$ Further research in this area is very much needed especially in the elements of the model in that the model will need some adjustments in order to be easily and comprehensively figured out.

$>\quad$ More pilot test should be conducted to find out a fit model for teaching English within the multidisciplinary courses of VHE.

> It is also needed to further study this model to teaching a specific subject like TOEFL, TOEIC, Debate, and other particular subject. A study on appropriate approach should be investigated.

Acknowledgment - This project under the scheme of competitive grant 2015 was awarded by Directorate of Research and Community Service (DITLITABMAS), Directorate of Higher Education of Indonesia (DIKTI) in association with LPPM (Centre for Research and Community Service) State Polytechnic of Ujung Pandang. This research had also been presented in 1st international conference on English and its educational dynamics (ICE-ed 2015) organized by English department, faculty of letters, Hasanuddin University.

\section{References}

Aboudan, R. (2011). Engage them, don't enrage them - student voices and what it takes to participate. English Language Teaching, 4, 128-134. http://dx.doi.org/10.5539/elt.v4n1p128

Bean, L. (2004). Engaging students in learning history. Journal of Business Administration Online, 2(2), 1-5.

Bond, T. G., \& M. Fox, C. (2015). Applying the rasch model:fundamental measurement in the human sciences. International Journal of Testing (Vol. 1). New York, NY: Routledge:Taylor \& Francis Group.

Boumová, V. (2008). Traditional vs modern teaching methods: Advantages and disadvantages of each. Masaryk University. Retrieved from https://is.muni.cz/th/86952/ff_m_b1/MgrDiplomkaBoumova.pdf

Braun, H., \& Kanjee, A. E., Bettinger, et al. (2006). Using assessment to improve education in developing nations. Improving education through assessment, innovation, and evaluation. Cambridge.

Chickering, A. W., \& Gamson, Z. F. (1987). Seven principles for good practice in undergraduate education. AAHE Bulletin, Mar, 3-7.

Davis, H. A., Summers, J., \& Miller, L. (2012). An interpersonal approach to classroom management: strategies for improving student engagement. Sage publication. Thousand Oaks: Corwin Press.

Dredger, K., Woods, D., Beach, C., \& Sagstetter, V. (2010). Engage me: using new literacies to create third space 
From ESA to ESCAPE: A conceptual model for teaching English in vocational higher education

classrooms that engage student writers. Journal of Media Literacy Education, 2(2), 85-101.

Fagerberg, J., \& Srholec, M., \& Verspagen, B (2010). The role of innovation in development. Review of Economics and Institutions, 1(2), 1-29. http://dx.doi.org/10.5202/rei.v1i2.2

Harmer, J. (1998). How to teach English: an introduction to the practice of english language teaching. Edinburgh, Harlow, Essex, England: Addison Wesley Longman Limited.

Harmer, J. (2007). How to teach English (2nd ed.). Edinburgh Gate, Harlow, Essex: Pearson, Longman.

$\mathrm{Hu}, \mathrm{P}$. (2011). English and vocational integration developing communicative competence. In Proceedings - 4th International Joint Conference on Computational Sciences and Optimization, CSO 2011 (pp. 704-708). http://dx.doi.org/10.1109/cso.2011.128

Huhta, M., \& Sciences, N. (2010). Language and communication for professional purposes: Needs analysis methods in industry and business and their yield to stakeholders. Helsinki University of Technology.

Kassim, H., \& Ali, F. (2010). English communicative events and skills needed at the workplace: Feedback from the industry. English for Specific Purposes, 29(3), 168-182. http://dx.doi.org/10.1016/j.esp.2009.10.002

Kehoe, D. (2007). Practice makes perfect: the importance of practical learning. The Social Market Foundation.

Lewis, A., \& Thompson, A. (2010). Activating strategies for use in the classroom. Retrieved from http://www.gcasd.org/Downloads/Activating_Strategies.pdf

Li, Y. W. (2016). Transforming conventional teaching classroom to learner-centred teaching classroom using multimedia-mediated learning module. International Journal of Information and Education Technology, 6(2), 105-112. http://dx.doi.org/10.7763/IJIET.2016.V6.667

Mohamed, A. A., Raha, N., Radzuan, M., Kassim, H., Musab, M., \& Ali, A. (2014). Conceptualizing English workplace communication needs of professional engineers : the challenges for english language tertiary educators. International Journal of Contemporary Business Management, 1(1), 1-9.

Parsons, J., \& Taylor, L. (2011). Student engagement: What do we know and what should we do ? Retrieved from https://education.alberta.ca/media/6459431/student_engagement_literature_review_2011.pdf

Perrone, V. (1994). How to engage students in learning. Educational Leadership, 51(5), 11.

Prensky, M. (2005). "Engage me or enrage me" what today's learners demand. Educause Review, 40, 60-65.

Rao, K., Hitchcock, C. H., Boisvert, P., Kilpatrick, E., \& Corbiell, C. (2012). Do it yourself: Video self-modeling made easy. Teaching Exceptional Children, 45(1). Retrieved from http://tecplus.org/article/2

Robertson, C., \& Acklam, R. (2000). Action plan for teachers: A guide to teaching english. London, UK: BBC World Service, British Broadcasting Corporation.

Rocca, K. A. (2010). Student participation in the college classroom: An extended multidisciplinary literature Review. Communication Education, 59(2), 185-213. http://dx.doi.org/10.1080/03634520903505936

Spiller, D. (2009). Assessment: Feedback to promote student learning. The University of Waikato. Retrieved from http://www.waikato.ac.nz/tdu/pdf/6_AssessmentFeedback.pdf

Sumintono, B., \& Widhiarso, W. (2013). Aplikasi model rasch untuk penelitian ilmu-ilmu sosial [Rasch model application to the study of social sciences]. Cimahi: Trim Komunikata Publishing House.

UP3AI. (2014). Annual report of teaching performance in State Polytechnic of Ujung Pandang. 
Musdariah, A., Anas, I., \& Muchtar, N. 